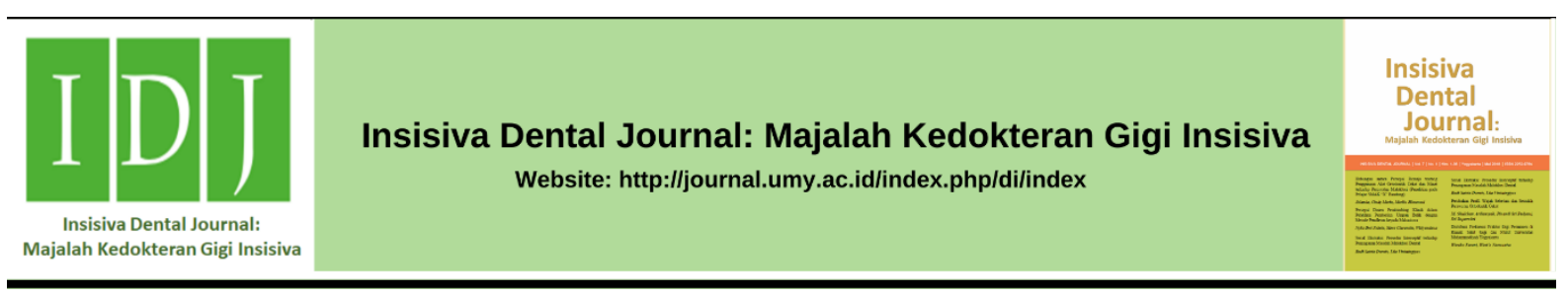

Research Article

\title{
Peningkatan Pengetahuan Kesehatan Gigi dan Mulut pada Lansia dengan Promosi Kesehatan Metode Demonstrasi
}

Increasing Oral Health Knowledge for Elderly with Health Promotion using Demonstration Method

\author{
Morita Sari*, Nendia Intan Permata Putri \\ Fakultas Kedokteran Gigi, Universitas Muhammadiyah Surakarta, Jalan Kebangkitan Nasional No. 101, Surakarta 57141, Indonesia.
}

Received date: March $10^{\text {th }}, 2021$; revised date: July $19^{\text {th }}, 2021$; accepted: November $9^{\text {th }}, 2021$

DOI: $10.18196 /$ di.v10i1.11311

\begin{abstract}
Abstrak
Penyakit mulut menyebabkan gangguan rasa sakit, fungsi menelan, makan, mencicipi, tersenyum dan komunikasi. Penyakit ini merupakan masalah utama masyarakat, khususnya di kalangan orang miskin, orang yang tinggal di pinggiran, dan lansia. Tujuan dari penelitian ini adalah untuk mengetahui efektivitas promosi kesehatan dengan metode demonstrasi terhadap peningkatan pengetahuan perilaku kesehatan gigi dan mulut pada lansia. Metode penelitian yang digunakan adalah penelitian pre-eksperimental dengan teknik total sampling. Pengukuran pengetahuan menggunakan kuisioner dilakukan sebelum dan sesudah dilakukan perlakuan yaitu demonstrasi cara melakukan sikat gigi yang baik dan benar. Jumlah sampel dalam penelitian ini sebanyak 45 subjek di ambil dari Panti Wredha, Dharma Bakti, Surakarta. Hasil penelitian dengan uji paired t-test menunjukkan perbedaan antara sebelum dan sesudah perlakuan dengan signifikansi $\mathrm{p}<0.05$. Berdasarkan hasil penelitian dapat disimpulkan bahwa promosi kesehatan metode demonstrasi terbukti efektif untuk meningkatkan pengetahuan lansia terhadap perilaku Kesehatan gigi dan mulut.
\end{abstract}

Kata Kunci: Lansia; Metode Demonstrasi; Perilaku Kesehatan Gigi dan Mulut; Promosi Kesehatan

\begin{abstract}
Oral health problems can lead to pain, such as swallowing disorder, eating and tasting disorder, smiling and communicating disorder. It is a primary disorder among people, especially in a lower-class society living in suburbs as well as elderly. This study aims to identify the effectiveness of health promotion using demonstration method to increase elderly's oral and dental health knowledge behavior. This research is a pre-experimental study using a total sampling technique. Oral health knowledge behavior was measured using a questionnaire at pre- and post-intervention in the form of an effective toothbrushing demonstration. The total sample in this research was 45 subjects selected from Panti Wredha, Dharma Bakti, Surakarta. Paired t-test showed significant differences between pre-and post-intervention with a value of $p<0.05$. Based on the result of this study, it can be concluded that health promotion using demonstration method was more effective for elderly to increase their knowledge and improve their behaviour in oral and dental health conditions.
\end{abstract}

Keywords: Dental and Oral Health Behavior; Demonstration Method; Elderly; Health Promotion.

\footnotetext{
${ }^{*}$ Corresponding author, e-mail: morita.sari@gmail.com
} 


\section{PENDAHULUAN}

Kesehatan merupakan aset dalam diri manusia ketika menghadapi tantangan kehidupan yang mencakup aspek fisik, sosial dan emosional. Menurut Konstitusi Organisasi Kesehatan Dunia yang ditetapkan pada tahun 1948, mendefinisikan kesehatan merupakan kondisi lengkap kesejahteraan fisik, mental, sosial dan bukan hanya karena tidak adanya penyakit yang dimiliki. ${ }^{-}$

Kesehatan mulut merupakan bagian integral dari kesehatan umum, ini dapat di buktikan bahwa resiko dan penyebab dari penyakit mulut sering berkaitan dengan penyakit umum. Kesehatan mulut dapat dipengaruhi oleh kesehatan keseluruhan, kesejahteraan, lingkungan keluarga, pendidikan, serta lingkungan. ${ }^{2}$ Penyakit mulut juga menyebabkan gangguan rasa sakit, fungsi menelan, makan, mencicipi, tersenyum dan komunikasi. Penyakit mulut merupakan masalah utama masyarakat, khususnya di kalangan orang miskin, orang yang tinggal di pinggiran, dan lansia. ${ }^{3}$

Definisi lansia adalah orang yang memiliki usia lebih dari 60 tahun dan secara fisik memiliki penampilan yang berbeda di bandingkan dengan kelompok umur yang lebih muda. ${ }^{4}$ Perubahan yang terjadi pada gigi akibat proses menua adalah atrisi, penyempitan ruang pulpa, penurunan gusi yang menyebabkan karies, penurunan fungsi kelenjar saliva. Perubahan yang terjadi tersebut menyebabkan lansia lebih mudah terkena karies yang meyebabkan kehilangan gigi lebih cepat. ${ }^{5}$ Lansia memiliki kesehatan mulut yang lebih buruk dibandingan dengan kalangan lainnya sebab sebagian besar dari mereka tidak memiliki kesadaran untuk menjaga gigi agar tetap sehat karena kurang pengetahuan yang disebabkan sudah tidak mendapatkan pendidikan. $\underline{6}$ Rata-rata lansia memiliki kondisi mulut yang buruk karena penumpukan plak, keadaan kronis yang tidak terkontrol dan kebersihan mulut yang buruk. Mereka juga memiliki kesadaran yang rendah untuk mencari layanan kesehatan gigi dan mulut. ${ }^{1}$
Meningkatkan status kesehatan adalah sesuatu yang perlu dalam keberlangsungan hidup untuk menjadikan generasi yang kuat. Masalah kesehatan di Indonesia semakin bertambah khususnya kesehatan gigi dan mulut. Kesehatan gigi dan mulut menjadi masalah paling atas yang tidak lain adalah masalah karies gigi. ${ }^{7}$ Gaya hidup yang positif di kalangan lansia berhubungan erat dengan manfaat kesehatan. Banyak penyakit diderita lansia yang dapat dicegah jika mereka melakukan gaya hidup yang sehat, misalnya menjaga aktivitas fisik dan pola makan dapat mencegah obesitas, penyakit jantung, hipertensi, diabetes sehingga dibutuhkan penyuluhan untuk meningkatkan pengetahuan lansia agar meningkatkan kualitas hidupnya. $\underline{8}$

Penyuluhan kesehatan adalah salah satu pendidikan kesehatan yang dilakukan untuk meningkatkan derajat kesehatan gigi dan mulut. Penyuluhan gigi dan mulut dilakukan pada kalangan orang normal atau berkebutuhan khusus yang disusun dan terencana dapat meningkatkan perilaku yang lebih menguntungkan untuk seseorang maupun kelompok. ${ }^{-}$Program promosi kesehatan memiliki peran yang penting untuk mengatur pengetahuan dan keterampilan yang mereka butuhkan untuk mendapat informasi tentang kesehatan. $\underline{10}$ Pelaksanaan promosi kesehatan, alat bantu dan media pendidikan sangat diperlukan untuk membantu responden menerima materi sehingga hasil yang diterima lebih efektif. $\underline{6}$

Metode penyuluhan secara garis besar dibedakan menjadi dua kategori yaitu sokratik dan didaktif. ${ }^{11}$ Teknik demonstrasi termasuk dalam teknik sokratik dimana metode demonstrasi merupakan teknik yang mempertunjukkan suatu cara dengan melihat langsung objek atau menunjukkan secara langsung prosedur dengan menggunakan alat peraga untuk menyampaikan materi. Alat peraga yang biasa digunakan dalam promosi kesehatan gigi dan mulut metode demonstrasi adalah phantom gigi. $\stackrel{9}{ }$ Penelitian ini bertujuan 
untuk mengetahui efektivitas promosi kesehatan dengan metode demonstrasi terhadap peningkatan pengetahuan kesehatan gigi dan mulut pada lansia.

\section{MATERIAL DAN METODE}

Jenis penelitian ini adalah penelitian pre eksperimental dengan rancangan satu kelompok pre dan post eksperimen. Populasi dalam penelitian ini adalah lansia di Panti Wredha Dharma Bhakti Kota Surakarta. Penelitian ini telah mendapatkan ethical approval dari Komisi Etik Penelitian Kesehatan RSUD Dr. Moewardi dengan Nomor 213/ II / HREC / 2020. Teknik pengambilan sample yang digunakan adalah total sampling dan didapat 45 sampel. Subjek penelitian telah menandatangani informed consent. Seluruh sampel dalam penelitian ini harus memenuhi kriteria inklusi; lansia yang memiliki pendengaran dan penglihatan yang baik, sedangkan sampel yang termasuk kriteria ekslusi yaitu lansia yang memiliki keterbatasan mental dan fisik untuk mengikuti penyuluhan, tidak diikutkan dalam penelitian.

Tahap persiapan penelitian adalah kalibrasi kuisioner dengan para surveyor dengan persamaan persepsi. Tahap pelaksanaan penelitian, semua sampel dilakukan pengukuran pengetahuan berupa perilaku menjaga kesehatan gigi dan mulut dengan mengisi kuisioner pre-test. Kemudian semua sampel diberikan promosi kesehatan mengenai cara menjaga kesehatan gigi dan mulut menggunakan metode demonstrasi berupa cara menyikat gigi yang benar. Pengisian kuisioner posttest semua sampel dilakukan setelah promosi kesehatan dengan demonstrasi selesai dilakukan.

Uji statistik yang di gunakan adalah uji paired t-test dengan uji normalitas menggunakan uji normalitas KolmogorovSmirnov. Semua data melalui tahapan pengolahan data dan di olah dengan software SPSS 16.

\section{HASIL}

Hasil pre-test sampel penelitian di dapatkan nilai tertinggi adalah 90 dan nilai terendah adalah 30 . Untuk frekuensi nilai pre-test terbanyak adalah 70 sebanyak 10 orang sedangkan frekuensi nilai pre-test tertinggi adalah 90 yaitu sebanyak 4 orang. Kemudian hasil post-test dari sampel penelitian di dapatkan nilai tertinggi yaitu 100 dan nilai terendah adalah 40. Nilai yang frekuensinya paling tinggi adalah responden yang mendapat nilai 80 yaitu sebanyak 13 orang, sedangkan nilai yang frekuensinya paling rendah adalah responden yang mendapat nilai 40 yaitu sebanyak 1 orang.

Uji statistik menggunakan paired $t$ test menunjukkan hasil yang signifikan yaitu $\mathrm{p}<0.05$ seperti pada tabel 1 .

Tabel 1. Ringkasan hasil uji paired t-test sebelum dan sesudah promosi kesehatan

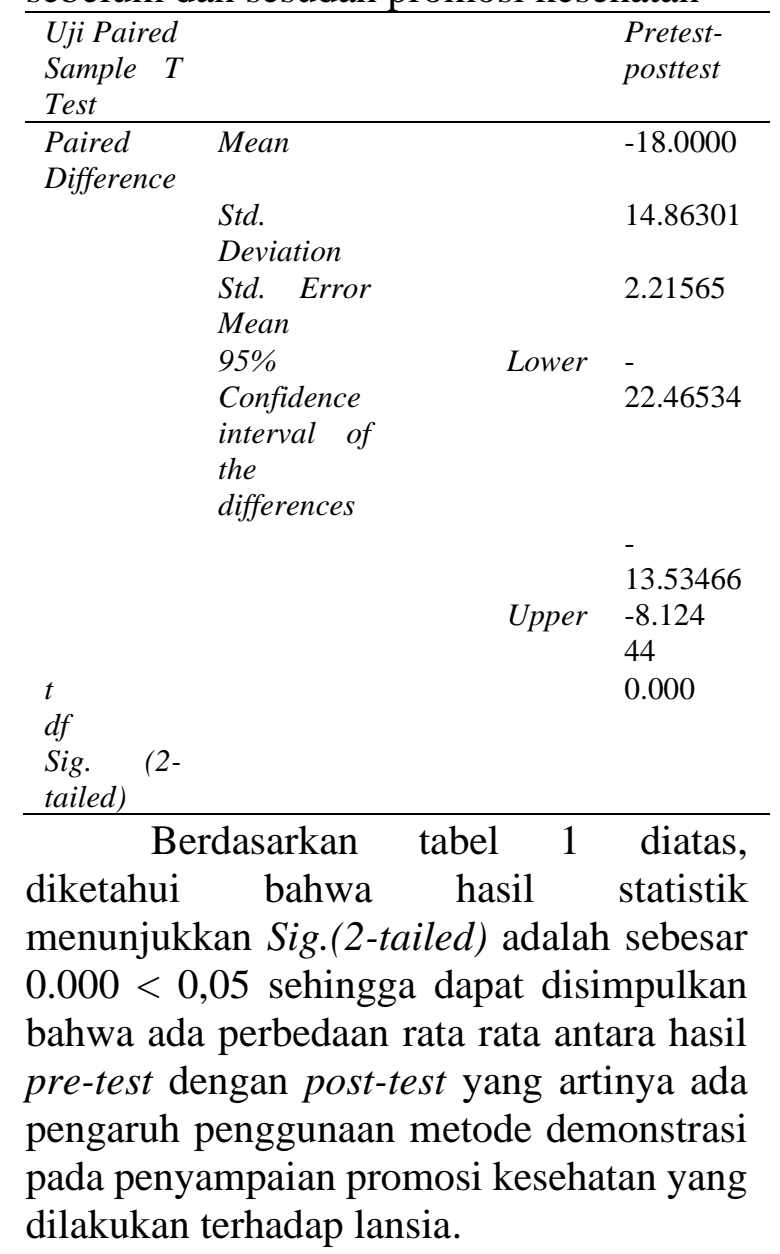




\section{PEMBAHASAN}

Lansia memiliki kesehatan mulut yang lebih buruk dibandingan dengan kalangan lainnya. $\frac{3}{}$ Proses penuaan yang terjadi pada lansia menyebabkan kerusakan di rongga mulut mereka. Penelitian yang dilakukan sebelumnya menyatakan bahwa orang yang lebih tua memiliki kondisi rongga mulut yang buruk. $\frac{12}{}$ Lansia tidak memiliki kesadaran untuk mencegah gigi agar tetap sehat karena kurang pengetahuan yang disebabkan sudah tidak mendapatkan pendidikan. $\underline{13}$

Hasil penelitian yang sudah dilakukan dalam peningkatan pengetahuan tentang cara menjaga kesehatan gigi dan mulut sebelum dan sesudah di berikan promosi kesehatan metode demonstrasi menunjukkan adanya peningkatan pengetahuan. Penyuluhan kesehatan gigi merupakan usaha terencana dan terarah untuk menciptakan suasana agar seseorang atau kelompok masyarakat mau mengubah perilaku menjadi lebih menguntungkan. ${ }^{14}$ Metode pembelajaran dalam penyampaian penyuluhan memegang peranan penting sebagai alat untuk menciptakan proses belajar mengajar yang efektif. .5 Media yang baik yaitu media yang tidak membosankan, namun dapat membuat penerima untuk berfikir, berinovasi, dan berkreasi. $\underline{6}$

Metode promosi kesehatan adalah sarana yang digunakan oleh petugas kesehatan untuk melakukan perubahan pada target sasaran. Metode adalah suatu cara menyampaikan informasi secara tidak langsung dan langsung menggunakan media sesuai yang di butuhkan. $\frac{15}{}$ Metode pembelajaran dalam penyampaian penyuluhan memegang peranan penting sebagai alat untuk menciptakan proses belajar mengajar yang efektif. ${ }^{16}$ Menurut penelitian yang dilakukan Hestiani (2017), yang menyatakan bahwa dalam metode demonstrasi dirancang sebagai salah satu model pendekatan yang baik dalam penyampaian materi untuk responden lansia sehingga hasil yang didapatkan akan efektif. ${ }^{17}$ Metode demonstrasi terbukti efektif meningkatkan pengetahuan dalam proses pemberian materi penyuluhan karena terdapat peningkatan nilai yang signifikan dari sebelum dan sesudah penyuluhan. Hasil penelitian ini sesuai dengan hasil penelitian yang dilakukan oleh Bany (2014) yang menyatakan bahwa metode penyuluhan dengan metode demonstrasi lebih efektif dari pada menggunakan ceramah. $\frac{18}{}$ Menurut penelitian Pratiwi (2019), metode demonstrasi memberikan hasil yang efektif karena metode demonstrasi memiliki keuntungan dalam proses penerimaan sasaran terhadap materi penyuluhan akan lebih berkesan secara mendalam, sehingga membentuk pengertian dengan baik dan sempurna. Selain itu responden melihat langsung proses suatu tahap dengan menggunakan benda tiruan sehingga akan memberikan hasil yang lebih efektif. ${ }^{-}$

Penelitian ini menunjukkan terdapat peningkatan nilai rata-rata pengetahuan pada sebelum dan sesudah penyuluhan pada masing masing kategori usia yaitu usia 5574 tahun dan 75-89 tahun. Data tersebut juga menunjukkan semakin tinggi usia akan menurunkan keefektifan dalam menerima materi. Berkurangnya pemahaman lansia dalam menerima informasi yang diberikan disebabkan karena berkurangnya kemampuan mendengar. $\frac{19}{}$ Lanjut usia bukan suatu penyakit, namun bersamaan dengan proses penuaan, insiden penyakit kronik dan ketidakmampuan akan semakin meningkat. $\frac{11}{11}$

Hasil uji paired t-test yang dihitung dengan menggunakan SPSS menunjukkan nilai Sig. $2=0,000(\mathrm{p}<0,05)$ sehingga dapat diartikan bahwa terdapat perbedaan yang signifikan antara rata-rata nilai sebelum perlakuan (pre-test) dengan nilai rata rata sesudah perlakuan (post-test). Kenaikan nilai rata- rata yang didapatkan lansia setelah perlakuan disebabkan karena meningkatnya pengetahuan dan pemahaman lansia tentag cara menjaga kesehatan gigi dan mulut setelah diberikan promosi kesehatan.

Penelitian ini memiliki kendala berupa tingkat konsentrasi responden 
dalam memperhatikan penyuluhan menyikat gigi. Faktor yang dapat menjadi alasan dibalik situasi ini adalah karakteristik dasar lansia yang pada umumnya memiliki gangguan atensi dan juga sulit dalam berkonsentrasi karena keterbatasan fisik yaitu pendengaran dan penglihatan sehingga pemateri harus menggunakan alat bantu suara agar volume suara lebih besar dan menggunakan media demonstrasi yang ukurannya besar supaya dapat didengar dan dilihat oleh lansia secara jelas. $\underline{8}$

Suatu proses pengajaran bisa dikatakan berhasil apabila jika pelajaran itu bisa membangkitkan proses belajar yang efektif. Hasil belajar digunakan oleh pemateri untuk dijadikan ukuran atau kriteria dalam mencapai suatu tujuan pendidikan..$^{3}$ Promosi kesehatan tentang menjaga kesehatan gigi dan mulut menggunakan metode demonstrasi terhadap tingkat pengetahuan lansia di Panti Wredha Dharma Bhakti Surakarta terbukti efektif terutama pada lansia yang memiliki usia 55-74. Hasil penelitian ini didukung oleh penelitian sebelumnya yang menyatakan bahwa usia lansia yang lebih dari 75 tahun memiliki resiko tinggi mengalami penurunan dalam berbagai hal termasuk pemenuhan aktivitas sehari-hari seperti menurunnya kemampuan mendengar dan melihat sehingga kesulitan menerima informasi. $\stackrel{11}{\text { Sebagian besar }}$ penyebab berkurangnya pemahaman lansia dalam menerima informasi yang diberikan adalah karena menurunnya kemampuan mendengar. $\underline{20}$

\section{KESIMPULAN}

Promosi kesehatan tentang menjaga kesehatan gigi dan mulut menggunakan metode demonstrasi terhadap peningkatan pengetahuan perilaku kesehatan gigi dan mulut terbukti efektif terutama pada lansia yang memiliki usia 55-74.

\section{DAFTAR PUSTAKA}

1. Huber M, Van Vliet M, Giezenberg M, et al. Towards a "patient-centred" operationalisation of the new dynamic concept of health: A mixed methods study. BMJ Open. 2016;6(1):1-11. https://doi.org/10.1136/bmjopen2015-010091

2. Ramadhan A, Cholil, sukmana BI. Hubungan Tingkat Pengetahuan Kesehatan Gigi dan Mulut terhadap Angka Karies Gigi di SMPN 1 Marabahan. Dentino J Kedokt Gigi. 2016;I(2):173-176.

http://dx.doi.org/10.20527/dentino.v1i 2.567

3. Kossioni AE, Hajto-Bryk J, Janssens $\mathrm{B}$, et al. Practical Guidelines for Physicians in Promoting Oral Health in Frail Older Adults. J Am Med Dir Assoc. 2018;19(12):1039-1046. https://doi.org/10.1016/j.jamda.2018.1 0.007

4. Yuditami NW, Arini NW, Wirata IN. Hubungan pengetahuan tentang pemeliharaan kesehatan gigi dan mulut dengan jumlah gigi yang berfungsi pada lanjut usia di panti pelayanan lanjut usia wana seraya biaung denpasar. $J$ Kesehat Gigi. 2015;3(2):70-75.

5. Asiking W, Rottie J, Malara R. Hubungan Merokok Dengan Kesehatan Gigi Dan Mulut Pada Pria Dewasa Di Desa Poyowa Kecil Kecamatan Kotamobagu Selatan Kota Kotamobagu. $J$ Keperawatan. 2016;4(1):1-6. https://doi.org/10.35790/jkp.v4i1.1080 $\underline{5}$

6. Putra DM, Juniarti N, Sari SP. Kebutuhan Masyarakat Sekolah Tentang Media Edukasi Dalam Meningkatkan Personal Hygiene Pada Anak Di SD Sukagalih. J Keperawatan Komprehensif. $\quad$ 2018;4(1):13-24. https://doi.org/10.33755/jkk.v4i1.94

7. Hestiani, Yuniar DN, Erawan PE meiyana. Efektivitas Metode Demonstrasi (sikat gigi) Terhadap 
peningkatan Pengetahuan, sikap dan tindakan terkait pencegahan Karien Gigi. J Ilm Mhs Kesehat Masy. 2107;2(5):2-4.

8. Kampmeijer R, Pavlova M, Tambor M, Golinowska S, Groot W. The use of ehealth and m-health tools in health promotion and primary prevention among older adults: A systematic literature review. BMC Health Serv Res. 2016;16(Suppl 5):290 https://doi.org/10.1186/s12913-016$\underline{1522-3}$

9. Pratiwi SL, Hatta I, Adhani R. Efektivitas Penyuluhan Menyikat Gigi Metode Horizontal antara Demonstrasi dan Video Terhadap Penurunan Plak. $J$ Kedokt Gigi. 2019;3(2):55-60.

10. Ogueta IC, Ramírez MP, Jiménez CO, Cifuentes MM. Geographic Tongue: What a Dermatologist Should Know. Actas Dermo-Sifiliográficas (English Ed. 2019;110(5):341-346. https://doi.org/10.1016/j.adengl.2019. $\underline{05.001}$

11. Nurbadriyah WD, Lestari $P$, Sufyanti Y. Pendekatan Calgary Family Intervention (CFIM) Tentang Pencegahan Foof Borne Disease dan Self Care Agency Anak. 2016;7(1):5569. https://doi.org/10.22219/jk.v7i1

12. Lacerda T e S. Factors Associated With the Presence of Dental Plaque in an Urban Cohort of Elderly (Epidoso). MOJ Gerontol Geriatr. 2017;1(3):6872.

https://doi.org/10.15406/mojgg.2017.0 1.00014

13. Sreenivasan PK, Prasad KVV, Javali SB. Oral health practices and prevalence of dental plaque and gingivitis among Indian adults. Clin Exp Dent Res. 2016;2(1):6-17. https://doi.org/10.1002/cre2.15

14. Kadek Wiwin Parianti N, Gede Ariyasa I, Ilmu Kesehatan F, Dan Teknologi Universitas Dhyana Pura
Bali S. Hubungan Kebiasaan Menyirih Terhadap Kejadian Karies Gigi Pada Lanjut Usia Di Desa Batubulan Kangin. J Virgin. 2015;1(2):24422509.

15. Shaalan SSA, El Tawil SB, Mahmoud SA. Effect of Dental Educational Program on Oral Hygiene Status Among Institutionalized Deaf Children. A Randomized Controlled Trial. Egypt Dent J. 2019;65(9):14.

16. Susilawati S, Damayanti MA, Azhari suhardjo RI. Pengaruh Penyuluhan Terhadap Tingkat Pengetahuan Siswa Tentang Kesehatan Gigi Dan Mulut Yang Dipengaruhi Radiasi. J Pengabdi Kpd Masy. 2017;1(6):398-401.

17. Sari DS, Mahdiyah Y, Arina D, et al. Hubungan Pengetahuan Kesehatan Gigi Mulut Dengan Status Kebersihan Rongga Mulut Pada Lansia. $J$ IKESMA. 2015;11(1):45.

18. Bany ZU, Sunnati, Darman W. Perbandingan Efektifitas Penyuluhan Metode Ceramah dan Demonstrasi Terhadap Pengetahuan Kesehatan Gigi dan Mulut Siswa SD. Cakradonya Dent J. 2014;6(1):661-666.

19. Nurlila RU, Fua J La, Meliana. Pengaruh Pendidikan Kesehatan terhadap Pengetahuan tentang Kesehatan Gigi pada Siswa di SD Kartika XX-10 Kota Kendari tahun 2015. J Al-Ta'dib. 2016;9(1):94-119. http://dx.doi.org/10.31332/atdb.v9i1.5 $\underline{04}$

20. Senjaya AA. Gigi lansia. J Skala Husada. 2016;13(1):72-80. 